\title{
Positron emission tomography/computed tomography for osseous and soft tissue sarcomas: A systematic review of the literature and meta-analysis
}

\author{
AIKEREMUJIANG MUHEREMU, JUNYI MA, AIERKEN AMUDONG, \\ YONG MA, MAIMAITIAILI NIYAZI, YONG OU and YUAN MA \\ Department of Spinal Surgery, The Sixth Affiliated Hospital of Xinjiang Medical University, \\ Urumqi, Xinjiang Uyghur Autonomous Region 86830001, P.R. China
}

Received November 18, 2016; Accepted May 22, 2017

DOI: $10.3892 / \mathrm{mco} .2017 .1329$

\begin{abstract}
In order to elucidate the value of positron emission tomography (PET)/computed tomography (CT) in the clinical diagnosis and treatment of osseous and soft tissue malignancies, two authors independently searched the PubMed, Medline, Elsevier, Embase and Cochrane Library databases for literature published between January 2003 and February 2016, using the key words 'PET/CT', 'positron emission tomography/computed tomography', 'osseous sarcoma', 'bone tumor', 'soft tissue sarcoma' and 'neoadjuvant', to identify prospective and retrospective studies on the applicability of PET/CT on the clinical diagnosis of bone and soft tissue lesions, and evaluation of their response to neoadjuvant therapies. Data were independently extracted by the two authors and any disagreements were resolved by a third author when necessary. Extracted data were analyzed by Meta-Disc 1.6 software. As a result, 16 trials with a total of 883 patients and 2,214 lesions were included in the present study. The overall diagnostic accuracy of PET/CT exhibited a sensitivity and specificity of 0.90 (0.86-0.92) and 0.89 (0.85-0.92), respectively, and the effect of neoadjuvant therapy was assessed with a sensitivity and specificity of $0.79(0.30-0.93)$ and 0.79 (0.69-0.89), respectively. Thus, it may be concluded from the present study that PET/CT is a reliable imaging method to be applied in the diagnosis and treatment of osseous and soft tissue malignancies.
\end{abstract}

Correspondence to: Dr Yuan Ma, Department of Spinal Surgery, The Sixth Affiliated Hospital of Xinjiang Medical University, 39 Wuxing Nan Lu, Urumqi, Xinjiang Uyghur Autonomous Region 86830001, P.R. China

E-mail: xinjiangspine@163.com

Key words: positron emission tomography/computed tomography, meta-analysis, diagnosis, treatment, bone tumors, sarcoma

\section{Introduction}

Osseous and soft tissue sarcomas are rare conditions that may easily be misdiagnosed. Apart from pathological observations of biopsies, imaging studies such as X-rays, whole-body bone scan, computed tomography (CT) and magnetic resonance imaging (MRI) are often used for diagnostic purposes in cases with osseous and soft tissue sarcomas. Positron emission tomography (PET) is an imaging method that semiquantitatively measures the metabolic rate of tissues by measuring the glucose intake level of cells in vivo. As malignant tumors normally have a higher metabolic rate compared with benign lesions and normal tissues, PET may theoretically be used to discriminate benign from malignant tumors and, by assessing the metabolic activity of tumor cells following neoadjuvant therapy, it may evaluate the treatment effect without invasive methods, such as biopsy. PET/CT is a combination of the $\mathrm{CT}$ and PET techniques, which is able to show the accurate anatomical structure and metabolic activity of the tissues in the whole body. As a new and sophisticated imaging diagnostic tool, PET/CT is gradually used in an increasing number of medical centers. In the current literature, extensive research has been performed on the application of PET/CT in the diagnosis of a variety of tumors, such as lung, colorectal and breast cancer, melanoma and lymphoma (1-3). However, due to the low incidence of primary malignant osseous sarcomas, there are only few reports with large patient samples on the diagnostic accuracy or treatment effect evaluation of PET/CT in osseous and soft tissue sarcomas.

\section{Data collection methods}

Literature search. Two independent reviewers performed a computerized search of databases including PubMed (2003-2016), Medline (2003-2016), Embase (2003-2016), Elsevier (2003-2016) and the Cochrane Library (2008-2016) with the mesh words: 'PET/CT', 'positron emission tomography/computed tomography', 'osseous sarcoma', 'bone tumor', 'soft tissue sarcoma' and 'neoadjuvant', for randomized controlled trials, half-randomized controlled studies, prospective and retrospective cohort studies on the accuracy 
of PET/CT for the diagnosis of bone and soft tissue sarcomas, and the evaluation of response to neoadjuvant therapy. For studies whose eligibility for the inclusion criteria failed to reach consensus between the two authors, a third author was invited to settle the disputes.

Study quality assessment. Two authors independently assessed the quality of the included studies by the Quality Assessment of Diagnostic Accuracy Studies (QUADAS) tool (4). Each study was scored as '+' (positive), '-' (negative) and '?' (unclear). In case of disagreement, a third author made the final decision. Studies with $<7$ ' + ' were considered to be of low methodological quality and high risk of bias. The methodological quality of the included trials is outlined in Table I.

Data extraction. Data in the included trials, including the authors of each study, study design, patient sample size, patient age, origin, time of follow-up and intervention methods, were extracted by two independent reviewers. Patient numbers with true-positive, false-positive, true-negative and false-negative diagnosis and evaluations in each study were extracted and recorded in specific tables. In case that the same patients were analyzed in more than one study, they were extracted and analyzed as one patient population.

Data were analyzed and processed by Meta-Disc software (5). Two authors checked the data input to ensure no errors were made. Considering the possibility of publication bias between the studies, the analyses were performed using the random-effects modes. The $\mathrm{I}^{2}$ test was used to test heterogeneity and studies were considered to have significant heterogeneity if $\mathrm{I}^{2}>50 \%$. Subgroup or sensitivity analysis was used in case of significant heterogeneity due to the methodological quality of the included trials. The differences in each study were defined by odds ratios (ORs) with $95 \%$ confidence intervals (95\% CIs) of the categorical outcome frequencies in the study groups and the control groups, respectively. The OR of each individual trial was shown in a forest plot.

\section{Results}

Results of the study selection process. Of the 1,310 articles screened, 16 (6-21) were selected for the final analysis (Fig. 1). The meta-analysis included a total of 883 patients and 2,214 lesions (Tables II and III). The majority of the studies were proven to be of relatively high quality according to the QUADAS quality assessment tool (Table I).

\section{Results of the meta-analysis}

Diagnostic accuracy. A total of 9 studies, including 738 patients with 2,069 lesions, investigated the diagnostic accuracy of PET/CT in osseous and soft tissue sarcomas (Table IV). On patient-based analysis, the overall sensitivity and specificity were $0.90(0.86-0.92)$ and $0.89(0.85-0.92)$. The area under the summary receiver operating characteristic (SROC) curve was 0.97, Q=0.91 (Fig. 2). On lesion-based analysis, the overall sensitivity and specificity were $0.96(0.94-0.97)$ and 0.95 (0.93-0.96). The area under the SROC curve was $0.97, \mathrm{Q}=0.88$ (. 3). The meta-analysis indicated that PET/CT is able to diagnose osseous and soft tissue sarcomas with high sensitivity and specificity.

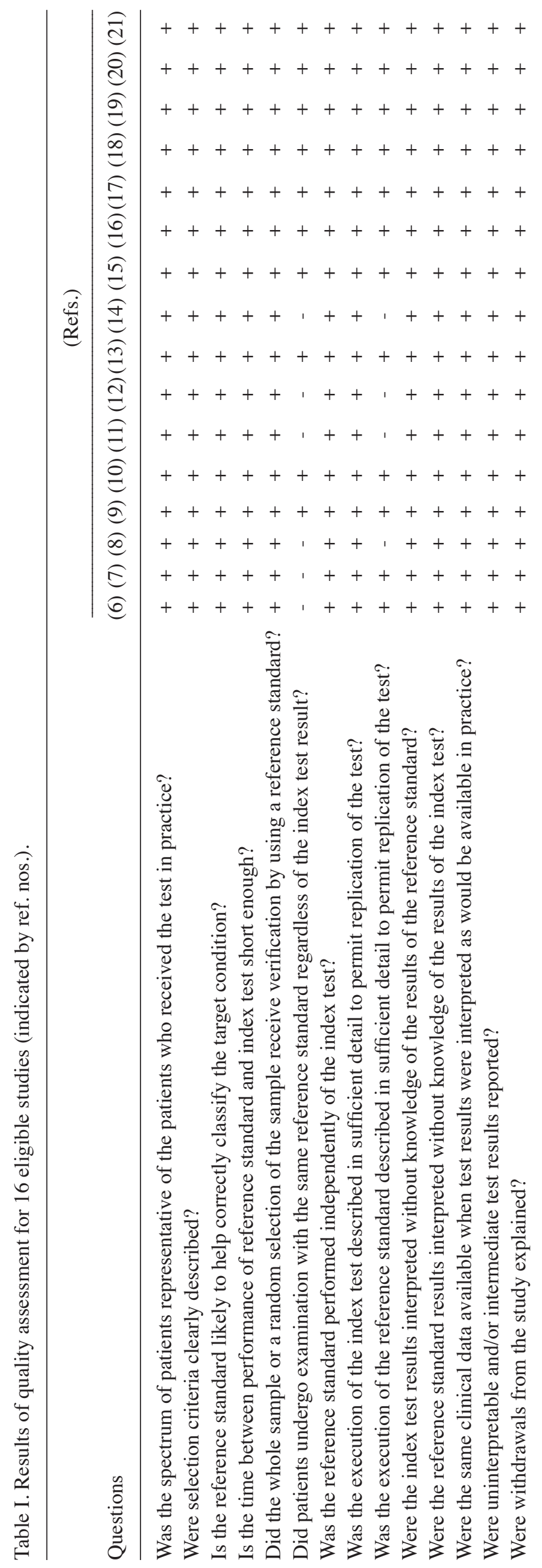


Table II. Demographic characteristics of the included studies.

\begin{tabular}{|c|c|c|c|c|c|c|}
\hline Authors & Patient no. & Age $^{\mathrm{a}}$, years & Study type & Patient enrollment & Time of study & (Refs.) \\
\hline Tateishi et al & 117 & $42 \pm 21$ & Prospective & Consecutive & Unclear & (6) \\
\hline Strobel et al & 50 & $36.9(11-72)$ & Prospective & Consecutive & Unclear & (7) \\
\hline Shin et al & 91 & $42(6-79)$ & Retrospective & Unclear & 2004.5-2007.6 & (8) \\
\hline Charest et al & 212 & $47 \pm 19.2$ & Retrospective & Consecutive & $2004.5-2008.4$ & (9) \\
\hline Pepirkova et al & 93 & $50.1 \pm 14.9$ & Retrospective & Unclear & 2004.1-2007.5 & (10) \\
\hline Fuglø et al & 89 & NA & Retrospective & Unclear & 2001.12-2010.12 & (11) \\
\hline Sharma et al & 53 & $20.1 \pm 10.5$ & Retrospective & Unclear & 2006.3-2012.1 & (12) \\
\hline $\mathrm{Xu}$ et al & 103 & $59.1 \pm 18.6$ & Retrospective & Unclear & 2007.3-2013.2 & (13) \\
\hline Byun et al & 206 & $15(4-71)$ & Retrospective & Consecutive & 2006.1-2011.11 & (14) \\
\hline Iagaru et al & 14 & $36 \pm 14$ & Retrospective & Consecutive & 1999.1-2004.12 & (15) \\
\hline Evilevitch et al & 42 & $17(7-31)$ & Prospective & Consecutive & 2005.1-2007.1 & (16) \\
\hline Hamada et al & 11 & $17(10.68)$ & Prospective & Consecutive & 2002.6-2006.8 & (17) \\
\hline Benz et al & 12 & $31.6 \pm 15.0$ & Prospective & Consecutive & 2005.2-2007.11 & (18) \\
\hline Im et al & 20 & $15(10-25)$ & Prospective & Consecutive & 2003.8-2010.7 & (19) \\
\hline Byun et al & 27 & $15(10-23)$ & Prospective & Consecutive & $2010.5-2012.3$ & (20) \\
\hline Byun et al & 31 & $15(10-21)$ & Prospective & Consecutive & $2010.5-2013.9$ & (21) \\
\hline
\end{tabular}

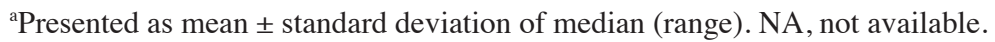

Table III. Characteristics of PET/CT imaging and of reference standards.

\begin{tabular}{|c|c|c|c|c|c|}
\hline Authors & $\begin{array}{c}\text { FDG } \\
(\mathrm{MBq})\end{array}$ & Measures & Reference standard & $\begin{array}{c}\text { Potential } \\
\text { verification bias }\end{array}$ & (Refs.) \\
\hline Tateishi et al & $300-370$ & Visualization, SUV & Histology and radiological follow-up & Very limited & $(6)$ \\
\hline Strobel et al & $350-400$ & Visualization, SUV & Histology, clinical and imaging follow-up & Very limited & (7) \\
\hline Shin et al & $8.1 / \mathrm{kg}$ & Visualization, SUV & Histology, clinical and imaging follow-up & Limited & (8) \\
\hline Charest et al & $370-500$ & Visualization, SUV & Histology & Very limited & $(9)$ \\
\hline Pepirkova et al & $370-555$ & Visualization, SUV & Histology & Very limited & $(10)$ \\
\hline Fuglø et al & $4.0 / \mathrm{kg}$ & Visualization, SUV & Histopathology, clinical and imaging follow-up & Limited & $(11)$ \\
\hline Sharma et al & 370 & Visualization, SUV & Histopathology, clinical and imaging follow-up & Limited & $(12)$ \\
\hline $\mathrm{Xu}$ et al & $3.5 / \mathrm{kg}$ & Visualization, SUV & Histopathological examination & Very limited & (13) \\
\hline Byun et al & $7.4 / \mathrm{kg}$ & Visualization, SUV & Histology, clinical and imaging follow-up & Very limited & $(14)$ \\
\hline Iagaru et al & 550 & Visualization, SUV & Histopathological examination of surgical specimen & Very limited & $(15)$ \\
\hline Evilevitch et al & $333-407$ & Visualization, SUV & Histopathological examination of surgical specimen & Very limited & $(16)$ \\
\hline Hamada et al & 370 & Visualization, SUV & Histopathological examination of surgical specimen & Very limited & $(17)$ \\
\hline Benz et al & $7.8 / \mathrm{kg}$ & Visualization, SUV & Histopathological examination of surgical specimen & Very limited & $(18)$ \\
\hline Im et al & $166-666$ & Visualization, SUV & Histopathological examination of surgical specimen & Very limited & $(19)$ \\
\hline Byun et al & 370 & Visualization, SUV & Histopathological examination of surgical specimen & Very limited & $(20)$ \\
\hline Byun et al & 370 & Visualization, SUV & Histopathological examination of surgical specimen & Very limited & $(21)$ \\
\hline
\end{tabular}

PET, positron emission tomography; CT, computed tomography; SUV, standardized uptake value.

Evaluation of response to neoadjuvant therapy. A total of 7 studies, including 145 patients, investigated the accuracy of PET/CT in assessing the treatment effect of neoadjuvant therapy on patients with osseous and soft tissue sarcomas (Table V). Generally, a ratio of maximum standardized uptake value (SUVmax) after therapy/SUVmax prior to therapy of $<0.5$ was considered as an indication of effective neoadjuvant therapy in the index test, and necrosis of $>90 \%$ in the intraoperative specimen was considered as an indication of effective neoadjuvant therapy in the reference test. The overall sensitivity and specificity were $0.79(0.30-0.93)$ and 0.79 (0.69-0.89), respectively. The area under the SROC curve was $0.87, \mathrm{Q}=0.80$ (Fig. 4). The meta-analysis indicated that PET/CT may be used to monitor the effect of neoadjuvant therapy in patients with osseous and soft tissue sarcomas with high sensitivity and specificity. 


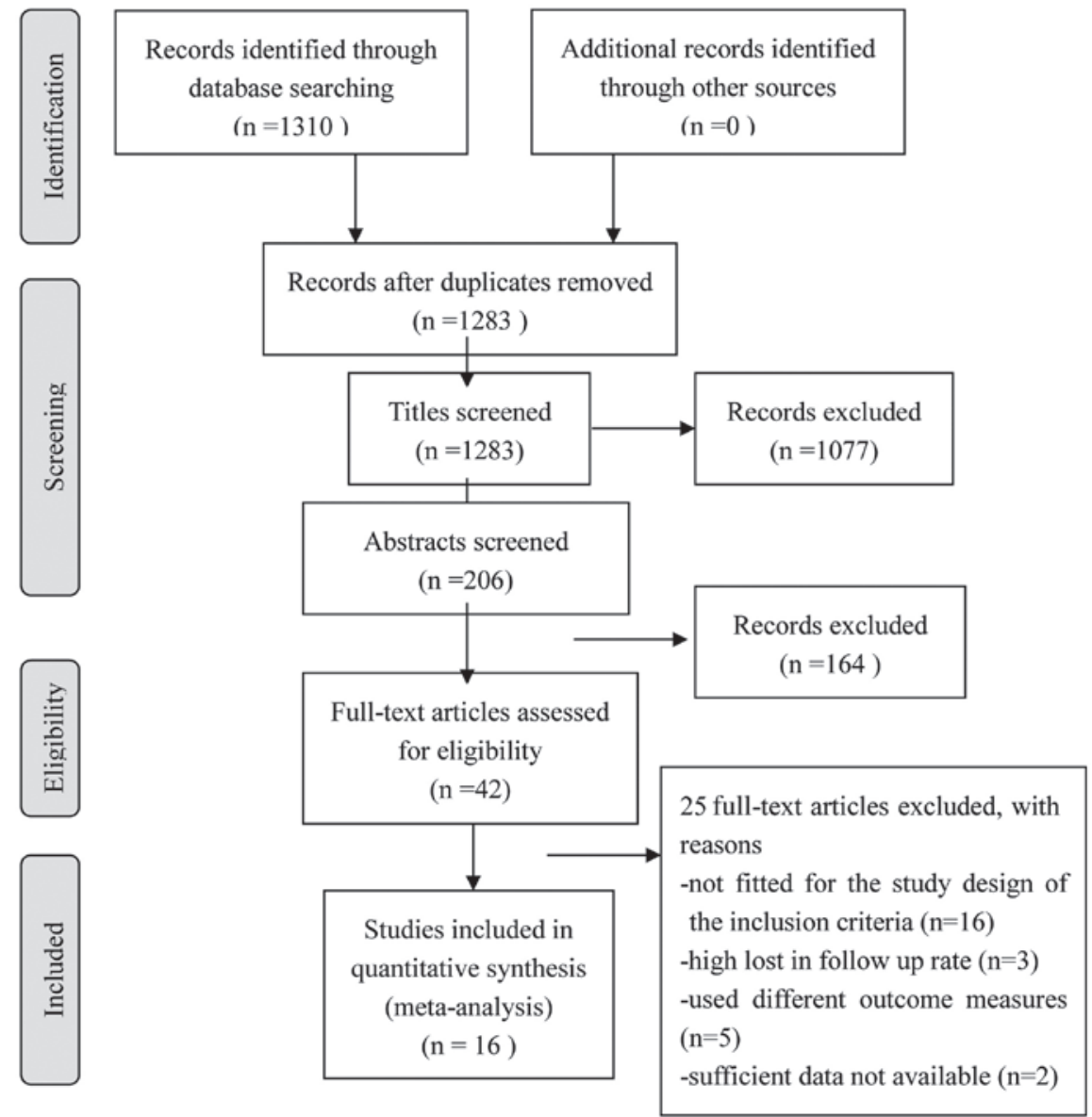

Figure 1. Flow chart of the selection of studies for the meta-analysis.

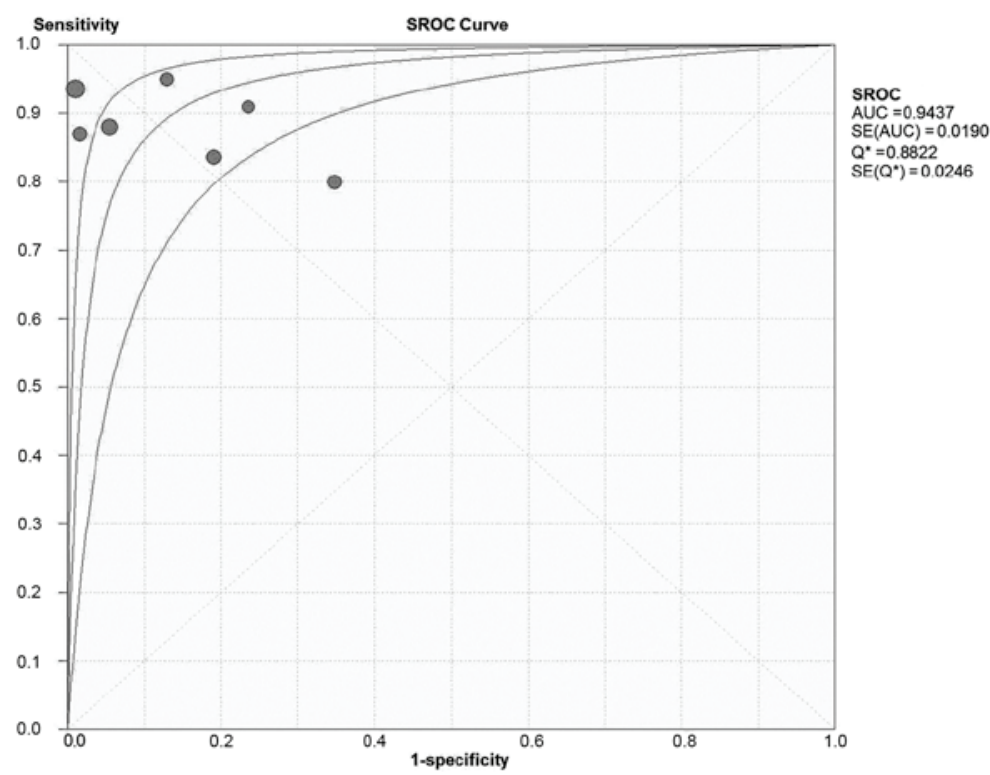

Figure 2. SROC curve of patient based analysis of the included studies. SROC, symmetric receiver operating characteristics curve; AUC, area under the curve; SE, standard error.

\section{Discussion}

Imaging studies are important for the diagnosis of various tumors. Currently, radiographic tests such as X-ray, CT and
MRI are widely applied for the diagnosis and treatment of musculoskeletal system malignancies (22).

${ }^{18} \mathrm{~F}$-fluorodeoxyglucose (FDG) PET is used for the semiquantification of glucose consumption by cells in the 
Table IV. Diagnostic accuracy of PET/CT on osseous and soft tissue sarcomas in the included studies.

\begin{tabular}{lcccccc}
\hline Authors & TP & FP & FN & TN & Sensitivity (95\% CI) & Specificity (95\% CI) \\
\hline Byun et al & 52 & 15 & 3 & 763 & $0.95(0.85-0.99)$ & $0.98(0.97-0.99)$ \\
Charest et al & 153 & 0 & 10 & 49 & $0.94(0.89-0.97)$ & $1.00(0.93-1.00)$ \\
Fuglø et al & 20 & 1 & 3 & 64 & $0.87(0.66-0.97)$ & $0.98(0.92-1.00)$ \\
Pepirkova et al & 424 & 0 & 3 & 71 & $0.99(0.98-1.00)$ & $1.00(0.95-1.00)$ \\
Sharma et al & 38 & 4 & 2 & 27 & $0.95(0.83-0.99)$ & $0.87(0.70-0.96)$ \\
Shin et al & 36 & 16 & 9 & 30 & $0.80(0.65-0.90)$ & $0.65(0.50-0.79)$ \\
Strobel et al & 30 & 4 & 3 & 13 & $0.91(0.76-0.98)$ & $0.76(0.50-0.93)$ \\
Tateishi et al & 44 & 4 & 6 & 69 & $0.88(0.76-0.95)$ & $0.95(0.87-0.98)$ \\
Xu et al & 51 & 8 & 10 & 34 & $0.84(0.72-0.92)$ & $0.81(0.66-0.91)$ \\
All cases & 372 & 37 & 43 & 286 & $0.90(0.86-0.92)$ & $(10)$ \\
All lesions & 848 & 52 & 49 & 1,120 & $0.95(0.93-0.96)$ & $(7)$ \\
\hline
\end{tabular}

PET, positron emission tomography; CT, computed tomography; TP, true-positive; TN, true-negative; FP, false-positive; FN, false-negative; CI, confidence interval.

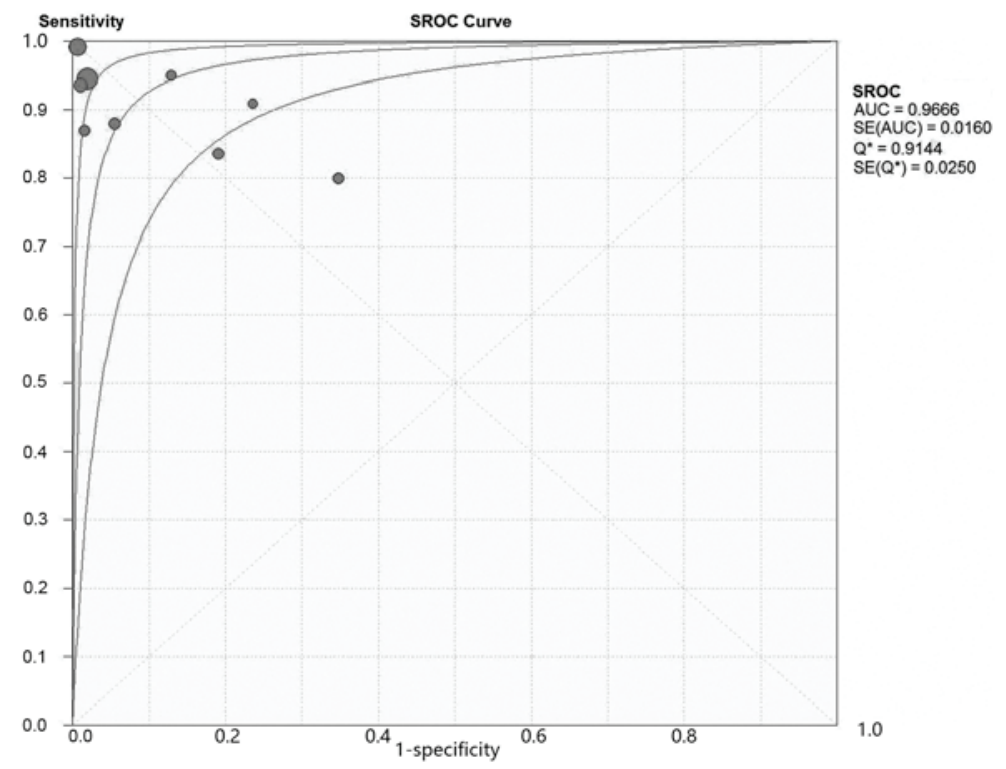

Figure 3. SROC curve of lesion based analysis of the included studies. SROC, symmetric receiver operating characteristics curve; AUC, area under the curve; SE, standard error.

body, which makes it possible to measure the enhancement of metabolic activity in cancer tissue. This is normally performed by calculating the SUVmax. ${ }^{18}$ F-FDG PET has been successfully used for the diagnosis of several types of cancer, such as lung cancer, melanoma, lymphoma, head and neck tumors, brain tumors, esophageal and colorectal cancer (23). The majority of the studies on the diagnostic value of PET in different types of tumors have concluded that it is a sensitive imaging modality for detection, staging and re-staging in oncology (24-26).

FDG-PET has been applied for diagnostic purposes in various malignant tumors since the early 90s (27). However, although ${ }^{18}$ F-FDG may locate abnormally functioning anatomical structures, the precise localization of the tumors may not be possible with PET alone. Combining PET with a high-resolution anatomical imaging modality, such as $\mathrm{CT}$, addresses this issue, provided that the images from the two modalities are accurately co-registered. Since 2003, a combination of PET and CT in one imaging device has gained increasing popularity and is referred to as integrated $\mathrm{PET} / \mathrm{CT}$. Integrated PET/CT is superior to PET or CT alone, as it can accomplish morphological and functional imaging in one procedure, and the images obtained with PET/CT were more accurate regarding localization of the tumor compared with PET and CT alone, or the fusion of PET and CT with software (28).

There are several reports on predicting the aggressiveness of musculoskeletal tumors by measuring the glucose consumption level using PET/CT (29). However, due to the low incidence of primary malignant osseous sarcomas and 
Table V. Accuracy of PET/CT assessment on the effect of neoadjuvant therapy on patients with osseous and soft tissue sarcomas in the included studies.

\begin{tabular}{lccccccc}
\hline Authors & TP & FP & FN & TN & Sensitivity (95\% CI) & Specificity (95\% CI) & (Refs.) \\
\hline Benz et al & 3 & 1 & 1 & 7 & $0.75(0.19-0.99)$ & $0.88(0.47-1.00)$ & $(18)$ \\
Byun et al & 8 & 2 & 4 & 13 & $0.67(0.35-0.90)$ & $0.87(0.60-0.98)$ & $(20)$ \\
Byun et al & 11 & 1 & 1 & 8 & $0.92(0.62-1.00)$ & $0.89(0.52-1.00)$ & $(21)$ \\
Evilevitch et al & 8 & 10 & 0 & 24 & $1.00(0.63-1.00)$ & $0.71(0.53-0.85)$ & $(16)$ \\
Hamada et al & 5 & 0 & 0 & 4 & $1.00(0.48-1.00)$ & $0.88(0.40-1.00)$ & $(17)$ \\
Iagaru et al & 3 & 1 & 3 & 7 & $0.50(0.12-0.88)$ & $0.88(0.47-1.00)$ & $(15)$ \\
Im et al & 6 & 4 & 3 & 7 & $0.67(0.30-0.93)$ & $0.64(0.31-0.89)$ & $(19)$ \\
Total & 44 & 19 & 12 & 70 & $0.79(0.30-0.93)$ & $0.79(0.69-0.89)$ & \\
\hline
\end{tabular}

PET, positron emission tomography; CT, computed tomography; TP, true-positive; TN, true-negative; FP, false-positive; FN, false-negative; CI, confidence interval.

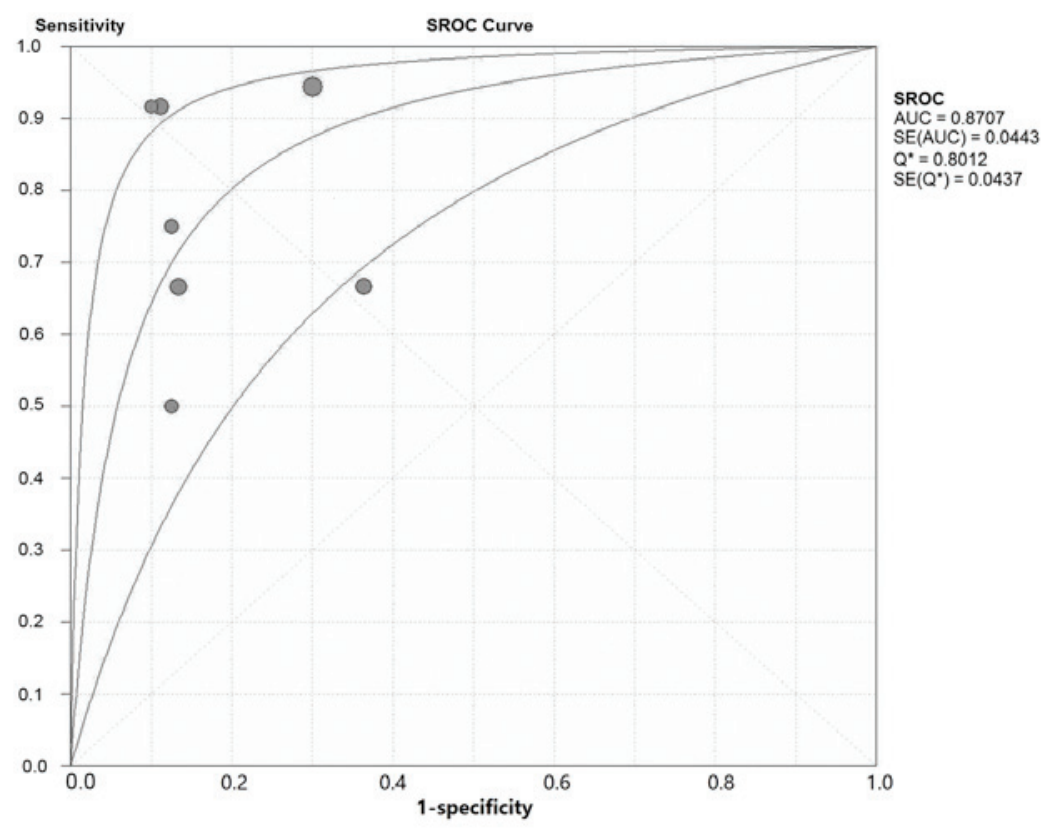

Figure 4. SROC curve on the assessment on the of neoadjuvant therapy effect.

the high cost of PRT/CT imaging, the majority of those studies included only a small number of patients; thus, the level of evidence obtained from those studies was greatly compromised.

The percentage of necrotic tissue following adjuvant therapy of tumors is one of the strongest prognostic factors of osteosarcoma (30). In the present study, PET/CT assessed the effect of neoadjuvant therapy with a sensitivity and specificity of $0.79(0.30-0.93)$ and 0.79 (0.69-0.89), respectively, indicating that PET/CT may be a reliable non-invasive method for evaluating the effect of neoadjuvant therapy on patients with osseous and soft tissue sarcomas. However, as only 145 patients were included in the meta-analysis, a larger sample is required to reach a more reliable conclusion.

Although the present study provided evidence on the applicability of PET/CT on the diagnosis and evaluation of response to neoadjuvant therapy for osseous and soft tissue sarcomas using the SUVmax value, and the quality of the included studies was relatively high, the overall sample size may be insufficient. Considering that osseous as well as soft tissue sarcomas are malignancies with a low incidence, multicenter prospective studies with longer follow-up are required to investigate the full potential of PET/CT in the diagnosis and treatment of musculoskeletal tumors.

In conclusion, PET/CT may be a reliable method with high accuracy for the diagnosis and evaluation of treatment efficacy for bone and soft tissue sarcomas, although the present findings require verification by larger-sample studies.

\section{Acknowledgements}

The present study did not directly involve any human or animal subjects. The study was approved by the Ethics Committee of The Sixth Affiliated Hospital of Xinjiang Medical University. 


\section{References}

1. Hoh CK, Schiepers C, Seltzer MA, Gambhir SS, Silverman DH, Czernin J, Maddahi J and Phelps ME: PET in oncology: Will it replace the other modalities? Semin Nucl Med 27: 94-106, 1997.

2. Brock CS, Meikle SR and Price P: Does fluorine-18 fluorodeoxyglucose metabolic imaging of tumors benefit oncology? Eur J Nucl Med 24: 691-705, 1997.

3. Bar-Shalom R, Valdivia AY and Blaufox MD: PET imaging in oncology. Semin Nucl Med 30: 150-185, 2000.

4. Whiting P, Rutjes AW, Reitsma JB, Bossuyt PM and Kleijnen J: The development of QUADAS: A tool for the quality assessment of studies of diagnostic accuracy included in systematic reviews. BMC Med Res Methodol 3: 25, 2003.

5. Zamora J, Abraira V, Muriel A, Khan K and Coomarasamy A: Meta-DiSc: A software for meta-analysis of test accuracy data. BMC Med Res Methodol 6: 31, 2006.

6. Tateishi U, Yamaguchi U, Seki K, Terauchi T, Arai Y and Kim EE: Bone and Soft-Tissue Sarcoma: Preoperative Staging with Fluorine 18 Fluorodeoxyglucose PET/CT and Conventional Imaging. Radiology 245: 839-847, 2007.

7. Strobel K, Exner UE, Stumpe KD, Hany TF, Bode B, Mende K, Veit-Haibach P, von Schulthess GK and Hodler J: The additional value of CT images interpretation in the differential diagnosis of benign vs. malignant primary bone lesions with 18F-FDG-PET/CT. Eur J Nucl Med Mol Imaging 35: 2000-2008, 2008.

8. Shin D, Shon OJ, Han DS, Choi JH, Chun KA and Cho IH: The clinical efficacy of (18)F-FDG-PET/CT in benign and malignant musculoskeletal tumors. Ann Nucl Med 22: 603-609, 2008.

9. Charest M, Hickeson M, Lisbona R, Novales-Diaz JA, Derbekyan V and Turcotte RE: FDG PET/CT imaging in primary osseous and soft tissue sarcomas: A retrospective review of 212 cases. Eur J Nucl Med Mol Imaging 36: 1944-1951, 2008

10. Piperkova E, Mikhaeil M, Mousavi A, Libes R, Viejo-Rullan F, Lin H, Rosen G and Abdel-Dayem H: Impact of PET and CT in $\mathrm{PET} / \mathrm{CT}$ studies for staging and evaluating treatment response in bone and soft tissue sarcomas. Clin Nucl Med 34: 146-150, 2009

11. Fuglø HM, Jørgensen SM, Loft A, Hovgaard D and Petersen MM The diagnostic and prognostic value of 18F-FDG PET/CT in the initial assessment of high-grade bone and soft tissue sarcoma a retrospective study of 89 patients. Eur J Nucl Med Mol Imaging 39: 1416-1424, 2012.

12. Sharma P, Khangembam BC, Suman KC, Singh H, Rastogi S, Khan SA, Bakhshi S, Thulkar S, Bal C, Malhotra A and Kumar R: Diagnostic accuracy of 18F-FDG PET/CT for detecting recurrence in patients with primary skeletal Ewing sarcoma. Eur J Nucl Med Mol Imaging 40: 1036-1043, 2013.

13. Xu R, Kido S, Suga K, Hirano Y, Tachibana R, Muramatsu K, Chagawa $\mathrm{K}$ and Tanaka S: Texture analysis on (18)F-FDG PET/CT images to differentiate malignant and benign bone and soft-tissue lesions. Ann Nucl Med 28: 926-935, 2014.

14. Byun BH, Kong CB, Lim I, Kim BI, Choi CW, Song WS, Cho WH, Jeon DG, Koh JS, Lee SY and Lim SM: Comparison of (18)F-FDG PET/CT and (99 m) Tc-MDP bone metastasis in osteosarcoma. Skeletal Radiol 42: 1673-1681, 2013.

15. Iagaru A, Masamed R, Chawla S, Menendez LR, Fedenko A and Conti PS: F-18 FDG PET and PET/CT Evaluation of Response to Chemotherapy in Bone and Soft Tissue Sarcomas. Clin Nucl Med 33: 8-13, 2008

16. Evilevitch V, Weber WA, Tap WD, Allen-Auerbach M, Chow K, Nelson SD, Eilber FR, Eckardt JJ, Elashoff RM, Phelps ME, et al: Reduction of glucose metabolic activity is more accurate than change in size at predicting histopathologic response to neoadjuvant therapy in high-grade soft-tissue sarcomas. Clin Cancer Res 14: 715-720, 2008.
17. Hamada $\mathrm{K}$, Tomita $\mathrm{Y}$, Inoue $\mathrm{A}$, Fujimoto $\mathrm{T}$, Hashimoto $\mathrm{N}$ Myoui A, Yoshikawa H and Hatazawa J: Evaluation of chemotherapy response in osteosarcoma with FDG-PET. Ann Nucl Med 23: 89-95, 2009.

18. Benz MR, Czernin J, Allen-Auerbach MS, Tap WD, Dry SM, Elashoff D, Chow K, Evilevitch V, Eckardt JJ, Phelps ME, et al: FDG-PET/CT imaging predicts histopathologic treatment responses after the initial cycle of neoadjuvant chemotherapy in high-grade soft-tissue sarcomas. Clin Cancer Res 15: 2856-2863, 2009.

19. Im HJ, Kim TS, Park SY, Min HS, Kim JH, Kang HG, Park SE, Kwon MM, Yoon JH, Park HJ, et al: Prediction of tumour necrosis fractions using metabolic and volumetric 18F-FDG PET/CT indices, after one course and at the completion of neoadjuvant chemotherapy, in children and young adults with osteosarcoma. Eur J Nucl Med Mol Imaging 39: 39-49, 2012.

20. Byun BH, Kong CB, Lim I, Choi CW, Song WS, Cho WH, Jeon DG, Koh JS, Lee SY and Lim SM: Combination of 18F-FDG $\mathrm{PET} / \mathrm{CT}$ and diffusion-weighted MR imaging as a predictor of histologic response to neoadjuvant chemotherapy: Preliminary results in osteosarcoma. J Nucl Med 54: 1053-1059, 2013.

21. Byun BH, Kim SH, Lim SM, Lim I, Kong CB, Song WS, Cho WH, Jeon DG, Lee SY, Koh JS and Chung SK: Prediction of response to neoadjuvant chemotherapy in osteosarcoma using dual-phase (18)F-FDG PET/CT. Eur radiol 25: 2015-2024, 2015.

22. Nishio J, Ideta S, Iwasaki H and Naito M: Scapular osteochondrolipoma: Imaging features with pathological correlation. Oncol Lett 6: 817-820, 2013.

23. Brenner W, Bohuslavizki KH and Eary JF: PET Imaging of Osteosarcoma. J Nucl Med 44: 930-942, 2003.

24. Fletcher JW, Djulbegovic B, Soares HP, Siegel BA, Lowe VJ, Lyman GH, Coleman RE, Wahl R, Paschold JC, Avril N, et al: Recommendations on the use of 18F-FDG PET in oncology. J Nucl Med 49: 480-508; 2008

25. Erdi YE: The use of PET for radiotherapy. Curr Med Imaging Rev 3: 3-16, 2007.

26. de Geus-Oei LF, van der Heijden HF, Corstens FH and Oyen WJ: Predictive and prognostic value of FDG-PET in nonsmall-cell lung cancer: A systematic review. Cancer 110: 1654-1664, 2007.

27. Hillner BE, Siegel BA, Shields AF, Liu D, Gareen IF, Hunt E and Coleman RE: Relationship between cancer type and impact of PET and PET/CT on intended management: Findings of the National Oncologic PET Registry. J Nucl Med 49: 1928-1935, 2008.

28. Boellaard R, O'Doherty MJ, Weber WA, Mottaghy FM, Lonsdale MN, Stroobants SG, Oyen WJ, Kotzerke J, Hoekstra OS, Pruim J, et al: FDG PET and PET/CT: EANM procedure guidelines for tumour PET imaging: Version 1.0. Eur J Nucl Med Mol Imaging 37: 181-200, 2010.

29. Muheremu A and Niu X: Positron emission tomography/computed tomography for bone tumors. Oncol Lett 9: 522-526, 2015.

30. Glasser DB, Lane JM, Huvos AG, Marcove RC and Rosen G: Survival, prognosis and therapeutic response in osteogenic sarcoma: The Memorial Hospital experience. Cancer 69: 698-708, 1992 